Dossiê: Narrativas

\title{
O que é narrativa?
}

\author{
What is narrative?
}

Corinne Squire*

\begin{abstract}
Resumo: Este artigo discute a definição e contornos da "narrativa". Inicialmente, ao se concentrar nos movimentos ou sucessões de signos narrativos e construção de sentidos, defende-se o descentramento da temporalidade e o reconhecimento de "narrativa" em imagens fotográficas, por exemplo. Em segundo lugar, considerando as particularidades das narrativas, o artigo discute como a pesquisa narrativa pode permitir transferibilidade e heurística, mais que generalização e preditibilidade. No caso de extrema particularidade de narrativas excepcionais, argumenta-se que estas operam como interruptores importantes de teorias existentes e propõe-se considerar fenômenos que não foram ainda considerados.
\end{abstract}

Palavras-chave: Narrativa. Particularidade. Exceção.

Abstract: This paper explores the definition and boundaries of 'narrative'. First, focusing on narratives' movement or succession of signs and building of meanings, it argues for the decentring of temporality and the recognition of 'narrative' in, for instance, still images. Second, taking into account the particularities of narratives, the paper examines how narrative research can allow for transferability and heuristics, rather than generalisability and predictivity. In the case of the extreme particularity of exceptional narratives, the paper argues that these operate as important interruptors of existing theory and calls to consider phenomena that have not yet been addressed.

Keywords: Narrative. Particularity. Exception.

* Doutora pela Exeter University (Devon, Reino Unido), professora de Ciências Sociais e codiretora do Centre for Narrative Research na University of East London, no Reino Unido. Publicações recentes incluem: Doing narrative research (com Andrews e Tamboukou; Sage, $2^{\mathrm{a}}$ ed. 2013) e Living with HIV and ARVs: three-letter lives (Palgrave, 2013) <c.squire@uel. ac.uk>. Traduzido do inglês por Luis Marcos Sander, com apoio do CNPq (edital 15/2011).

\begin{tabular}{|c|c|c|c|c|c|}
\hline Civitas & Porto Alegre & v. 14 & n. 2 & p. 272-284 & maio-ago. 2014 \\
\hline
\end{tabular}


Neste artigo, pretendo examinar dois aspectos da narrativa que se relacionam com definições comuns dela a fim de desconstruir estas definições e reconfigurá-las de uma outra maneira.

Iniciarei com uma definição muito ampla de narrativa como uma cadeia de signos com sentidos sociais, culturais e/ou históricos particulares, e não gerais. Esta definição significa que narrativas podem implicar conjuntos de signos que se movimentam temporalmente, causalmente ou de alguma outra forma socioculturalmente reconhecível e que, por operarem com a particularidade e não com a generalidade, não são reduzíveis a teorias. Nesta definição, a narrativa pode operar em várias mídias, inclusive em imagens imóveis. Ela deriva simplesmente da sucessão de signos, independentemente do sistema de símbolos, da mídia ou da "matriz semiótica" em que esta sucessão ocorre. No entanto, em uma narrativa, o movimento de signo para signo tem um significado social, cultural e histórico reconhecível. Uma série numérica é uma progressão de signos, mas seu sentido primordial é matemático e não se encontra em âmbitos sociais, culturais ou históricos. Um corolário desta definição é que as histórias não têm vigência universal; elas se valem de recursos simbólicos sociais, culturais e históricos particulares e operam dentro deles. A "leitura" de histórias pode, portanto, mudar ou se romper entre universos sociais, culturais e históricos distintos. Nessa definição, materiais visuais certamente podem constituir narrativas.

Em muitas explicações de narrativa, privilegia-se a progressão temporal das histórias; eu, porém, não a estou priorizando na definição acima. As vidas se desenvolvem no tempo, e assim o fazem o ouvir ou ler histórias, e a capacidade das histórias de andar paralelamente ao curso da vida nesta dimensão muitas vezes é entendida como determinante do valor delas. Mas apenas porque elas acontecem no tempo, isso não significa que o tempo seja seu principal princípio organizador. Afinal, elas também acontecem no espaço, e os pesquisadores de narrativas muito mais raramente gastam tempo explorando os paralelos entre as dimensões espaciais de corpos e vidas, e a extensão espacial de vozes, da escrita, da imagem. Além disso, a não linearidade de narrativas aparentemente dispostas temporalmente também é reconhecida como altamente significativa na teoria literária e cultural, como no caso do romance pós-século 19, ou nas formas em que os artistas cômicos muitas vezes interrompem a codificação temporal de imagens da esquerda-para-a-direita, de cima-para-baixo, ou, de modo mais complexo, as lacunas nas sequências de fotografias que Jo Spence (1995) fez de suas experiências com o câncer. As explicações psicanalíticas do filme também sugerem que ele é um meio preeminentemente adequado para examinar os timings flexíveis do inconsciente. A temporalidade, portanto, 
evidentemente não consegue explicar o poder narrativo inclusive de imagens em movimento - a não ser que reformulemos tudo que não seja abrangido por ela como outras formas de temporalidade, o que é uma medida que meramente a restabelece como um princípio organizador.

As imagens imóveis talvez sejam os casos mais interessantes para examinar em termos de narrativa fora da temporalidade - isso se excetuarmos aquelas versões delas que são claramente marcadas de modo temporal, como, por exemplo, um momento em uma história verbal mais longa, ou uma vida; ou aquelas imagens que estão cercadas pelo texto explicador que "conta a história delas". Como ressaltou Rosalind Krauss (1993), pode haver movimento dentro de imagens imóveis. Escrevendo sobre as fotografias de "desastre" de Cindy Sherman, que recriam, com fracasso mimético e excesso, pinturas anteriores da "história", Krauss descreve uma "erosão da forma a partir de dentro" nestas imagens imóveis à medida que elas passam para "a ausência de forma", colocada em movimento descensional pelas "forças" gravitacionais "do horizontal". Isto gera outro tipo de sucessão narrativa, em direção, como Barthes (2009) diria de forma mais geral, à morte, dentro das fotografias. ${ }^{1}$

As fotografias posteriores de Sherman de materiais ambíguos, abjetos e em decomposição, delineiam progressões semelhantes de forma mais explícita, e sem as conotações historicizantes da série "desastres" que poderiam ser entendidas como temporalização implícita. Nestas fotografias posteriores, progressões de decadência ocorrem ao longo de toda a imagem, mas elas não são temporalmente marcadas e não necessitam ser lidas como tal. ${ }^{2}$

De modo semelhante, a recente série radiofônica da BBC Uma história do mundo em 100 objetos (MacGregor, 2011), produzida com o Museu Britânico, permitiu que esses objetos apresentassem narrativas cristalizadas dentro de si. É claro que existem histórias escritas sobre os objetos, e elas também podem ser encaixadas em narrativas históricas mais amplas. No entanto, as marcas visíveis que os objetos carregam mostram suas narrativas até certo ponto, independentemente das outras histórias em torno deles. Este tambor da África Ocidental, por exemplo, demonstra sua origem na madeira de que é feito. Sua pele, que reflete o próximo estágio em sua jornada e uma complexa e indeterminada história dentro da escravidão, é norte-americana. A localização do objeto no Museu Britânico indica a ação de coleta de ricos comerciantes ingleses com base nos Estados Unidos da América, os quais

1 Ver o Autorretrato histórico, de Cindy Sherman (Sherman's Untitled 210, 1989 <www.moma. org/interactives/exhibitions/2012/cindysherman/gallery/7/2-210.php >).

2 Ver Boneca e detritos, de Cindy Sherman (Sherman's Untitled 175, $1987<$ www.moma.org/ interactives/exhibitions/2012/cindysherman/gallery/6/\#/1/untitled-175-1987>). 
muitas vezes também estavam envolvidos com a escravidão. Uma parte desta história está notavelmente escrita dentro do objeto; grande parte não está, mas estas disjunções históricas também figuram, às vezes, dentro do objeto, por exemplo, na desconexão entre a madeira e a pele. ${ }^{3}$

Laura Mulvey (2006) sugeriu que as tecnologias visuais contemporâneas enfatizam algumas formas diferentes, "postergadas" de examinar imagens em movimento. Pausar imagens em movimento, repeti-las, dar um close nelas, desconstruir imagens e recombiná-las - estes processos enfatizam como os significados podem ser deferidos e reconfigurados. Eles sugerem uma maneira mais reflexiva, "pensativa" de se relacionar narrativamente com imagens. Portanto, processos contemporâneos de leitura de imagens mostram como podemos ler narrativas de maneiras alteradas, fragmentadas e abertas. Mulvey se refere primordialmente a imagens em movimento, mas imagens e objetos imóveis oferecem uma possibilidade narrativa deferida semelhante, repetidamente estimulada pelas diferenças dentro da imagem ou objeto que uma leitura "pensativa" coloca em primeiro plano - por detalhes sutis dentro dela ou dele, por exemplo.

Esta explicação da narrativa se afasta do que talvez seja a dominância sócio-historicamente específica da temporalidade "pura" em estudos narrativos, sustentada em ideias sociocientíficas sobre a narrativa durante mais tempo do que em algumas outras áreas (Mitchell, 1987; Fried, 2012). A ausência de temporalidade colocada em primeiro plano em imagens visuais imóveis e especialmente objetos nos permite examinar outras possibilidades -espacialidade, progressões conceituais, coconstruções interpessoais- como organizadores narrativos primordiais.

Anthony Appiah fala sobre as possibilidades abertas de leituras futuras do tambor Akan. Muitas vezes se afirma que objetos e imagens gerarão, mais provavelmente do que materiais verbais, leituras narrativas cambiantes ou fragmentadas mediante sua "abertura" - isto é, através do conjunto muito maior de significantes a que cada significado se conecta em potencial. Este truísmo talvez derive sua força da confortadora, mas enganosa familiaridade de certos tipos de interpretação de linguagem, e não de interpretação visual ou de objetos, dentro das culturas ocidentais contemporâneas - e também de longas histórias dentro dessas culturas de argumentação sobre as funções e status relativos de palavras e imagens (Derrida, 1987; Mitchell, 1987). Quando começamos a ler em detalhes, em níveis diferentes, aquilo que não está lá

3 Ver Tambor Akan, de Cindy Sherman (Sherman's Untitled 175, 1987 <www.moma.org/ interactives/exhibitions/2012/cindysherman/gallery/6/\#/1/untitled-175-1987>). 
assim como aquilo que está, deixa de ser óbvio que histórias verbais permitem leituras mais estáveis e definidas do que narrativas visuais ou de objetos. A multiplicidade, a fratura e a contradição caracterizam narrativas em todas as mídias. As narrativas são todas formadas a partir de sinais cujas próprias desarticulações são aumentadas pelas cadeias de sinais que constituem as histórias.

Vou examinar agora o lugar das exceções em narrativas, especialmente em relação à epidemia do HIV, meu principal campo de pesquisa, cuja excepcionalidade é ela própria, muitas vezes, o tema de debate. Em relação a esta epidemia, penso que podemos ver histórias excepcionais atuando em, pelo menos, duas formas diferentes e valiosas.

A importância da particularidade em histórias, que em sua forma mais aguda se manifesta como exceções, é amplamente reconhecida por pesquisadores de narrativas - a particularidade das histórias é, de fato, o que distingue a narrativa da teoria, por exemplo, para Bruner (1990). Penso que esta distinção é útil - a narrativa geralmente é diferenciada da teoria, precisamente na medida em que explica através da especificidade. Mas a distinção não é plenamente sustentável. Meu próprio trabalho e o de muitas outras pessoas estão sempre preocupados com múltiplos casos de narrativas estudadas através de múltiplos participantes - não tantos quantos seriam abordados em um estudo quantitativo, é claro, mas um número semelhante ao que caracteriza muitos estudos qualitativos. Nesse trabalho, os pesquisadores não estão visando à generalizabilidade, que se baseia em convenções definidas de amostragem e importância - embora estas, naturalmente, difiram marcantemente entre as ciências sociais, naturais e físicas. Em vez disso, este tipo de trabalho se baseia no que, muitas vezes, é chamado de transferibilidade (Lincoln e Guba, 1985) ou seja, a possibilidade para que públicos e, muitas vezes, para que os próprios pesquisadores relacionem achados de um contexto com aqueles de outro contexto, façam conexões que possam oferecer formas de compreender outros achados em outros contextos e que possam inclusive sugerir que achados podem surgir neles. Isto não é generalizabilidade ou preditividade, mas são, antes, versões pragmáticas delas que as reformulam como transferibilidade e especulação informada.

Nessas circunstâncias, as narrativas, analisadas em múltiplos casos, podem produzir heurísticas de fenômenos, senão teorias. Em todo caso, as teorias ocorrem em múltiplos níveis, e muitas delas estão bastante próximas de serem heurísticas, especialmente nas ciências sociais. A possibilidade oferecida por essas heurísticas de ir além da descrição e singularidade ao se pesquisar narrativas é importante. Mas o papel da especificidade e das exceções não 
parece forte nessa explicação. No entanto, é o fato de as narrativas estarem arraigadas no particular que lhes permite trazer para a pesquisa fenômenos que são novos, ignorados ou recalcitrantes devido à sua complexidade e opacidade. É essa particularidade arraigada que permite à pesquisa das narrativas tornar-se mais ou diferentemente transferível, construir heurísticas melhores.

Também há uma grande quantidade de pesquisa de narrativas que está muito mais claramente fundada na particularidade: pesquisa sobre histórias, biografias e casos específicos. A obra de Elliot Mishler (1999) é exemplar na argumentação em favor da importância da variabilidade na pesquisa de narrativas, mostrando que essa pesquisa não está apenas fazendo o que a maior parte da pesquisa qualitativa faz de qualquer maneira, mas está contribuindo com algo realmente distintivo em sua busca exaustiva do que se segue na história, da outra história, da história não contada ou não ouvida. Penso que isso é interessantemente diferente do que a particularidade antropológica oferece, embora essa seja uma distinção que necessite ser mais desdobrada do que se pode fazer aqui.

Essa variabilidade e particularidade funcionam de duas maneiras aparentemente diversas. Às vezes, elas são emblemáticas. Parte deste processo emblematizador implica a inclusão da excepcionalidade. A natureza excepcional de algumas histórias ajuda a apoiar argumentos, porque sugere a generalidade em todas as circunstâncias altamente idiossincráticas desses argumentos. Assim, nesses casos, histórias são encontradas ou construídas e usadas para ilustrar ou resumir uma verdade mais geral, como quando os pesquisadores tendem a usar extratos de histórias ao descreverem padrões narrativos em um amplo conjunto de dados. Mas está claro que, nesses casos, a história individual realmente não importa para o argumento, mesmo que seja aquilo que os leitores lembram; e também que uma história pode ser usada para reforçar alguns argumentos bastante questionáveis, porque a dependência de histórias tende a desviar a atenção dos leitores, tanto logicamente quanto por causa do simples espaço das colunas que as histórias ocupam. Os pesquisadores de narrativas não estão imunes a essas falhas.

A outra maneira em que a particularidade narrativa funciona é explicitamente como exceção - ou seja, para enfatizar fenômenos radicalmente distintos e não para ilustrar fenômenos gerais. Este tipo de particularidade implica histórias não assimiláveis que apontam para fora do marco teórico usual. Essas histórias podem ser problemáticas para pesquisadores de narrativas. Às vezes, os pesquisadores realmente poderiam ser aconselhados a eliminar essas histórias de seu conjunto de dados, tal é sua atipicidade. Seu alcance teórico é aparentemente limitado -elas podem apoiar somente 
uma explicação preliminar, de um só caso- mas sua importância para testar e desenvolver a teoria -ou heurística- é grande. Ao confundir as coisas, elas contestam explicações existentes e expandem o escopo de explicações futuras.

Examinando mais amplamente o material narrativo, creio ser útil pensar sobre essas exceções narrativas como jamais plenamente excepcionais, e sobre a excepcionalidade radical como algo que aparece inclusive em material aparentemente mais emblemático, transferível. As exceções narrativas derivam sua força das convenções que abandonam; as convenções narrativas derivam sua força de suas exceções. (Isso talvez seja a maneira como a noção de excepcionalidade difere mais claramente daquela da análise de casos desviantes - Lincoln e Guba, 1985). Nussbaum (1998) sustentou algo semelhante no caso da tragédia. As circunstâncias do sofrimento podem ser barrocas e distantes, genuinamente excepcionais, diz ela, mas isso apenas sublinha o caráter comum do próprio sofrimento, e das tentativas agênticas embora malfadadas dentro da tragédia para superá-lo. Na Tent city university do Occupy London, em uma oficina sobre histórias, contei uma história sobre uma mulher soropositiva na África do Sul especificamente para vermos se a alteridade radical do material fazia qualquer sentido narrativo naquele contexto. Foi, com efeito, a forte ausência de familiaridade dos detalhes da história que reforçou a linha narrativa comum que os ouvintes extraíram: que acontecimentos terríveis podem ser aceitos, transcendidos e inclusive usados para moldar um caminho de vida progressivo. Por sua vez, este funcionamento dialético da convenção narrativa com a exceção dificilmente constitui uma percepção nova ou original. Mishler (1999), apresentando material de histórias de vida individualmente singulares de artesãos, enfatiza que, em meio a toda esta disparidade, a ocorrência comum de momentos cruciais em narrativas de vida, por exemplo, é evidente para leitores em circunstâncias muito diferentes.

Por outro lado, momentos de excepcionalidade muitas vezes podem ser reconhecidos inclusive nas narrativas mais convencionais. Eles são os significantes que caem fora da história sem ter um sentido claro, os elementos ilegíveis que ou permanecem na cabeça ou são imediatamente esquecidos, como os puncta que Barthes (2009) descreve em fotografias. É nisso que a leitura em busca da excepcionalidade, que Schor (2006) chama de leitura em detalhe, se torna importante para todo trabalho narrativo, esteja ele baseado em pequenas ou grandes histórias, em casos ou bases de dados grandes.

A recalcitrância ao sentido é, com efeito, o apelo, diria eu, da particularidade de histórias - os elementos não incorporáveis delas. Muitos críticos da virada narrativa -Craib (2004), Frosh (2002), Cowen (2009)- sugerem que somos seduzidos pelo encerramento e previsibilidade das histórias, ao 
passo que as vidas são confusas, rudimentares e sem sentido. Mas um corpo crescente de pesquisa e, realmente, todo o nosso trabalho no CNR (Centro de Pesquisa de Narrativas), diria eu, enfatiza a incoerência, a multiplicidade e as contradições intrínsecas das histórias (Hyvärinen et al., 2010). Neste tocante estamos nos valendo de ideias literário-teóricas bem estabelecidas sobre as descontinuidades dentro da linguagem, incluindo a linguagem narrativa (Butler, 2005). No meu caso, particularmente em relação a narrativas a respeito do HIV, me foi útil o trabalho da analista e teórica literária Julia Kristeva (1984) ao tentar ler histórias como redes provisórias de sentido lançadas sobre abismos de abjeção não representável.

É claro que há prazeres de repetição e encerramento em narrativas, mas é interessante que a repetição exata, o encerramento exato, não é o que geralmente exigimos de histórias. Mesmo para as crianças, a muito desejada repetição de uma história sempre está acontecendo em outro contexto que (como Derrida o expressa em Cornell, 2005) descortina outro sentido. Mesmo em tradições orais muitas vezes caricaturizadas como reprodutoras fiéis de narrativas, a inovação é valorizada juntamente com a familiaridade. Como poderíamos esperar, então, o poder recuperativo das histórias, bem captado no livro de McAdams (2006) sobre narrativas de redenção, sempre é respaldado e sombreado pelos efeitos mais disruptivos das histórias. Cowen diz que nós evitamos os "mapas complexos de histórias" que são realmente necessários para fazer jus aos fenômenos; creio que essa complexidade é em si atraente, mesmo que ela esteja implícita e encoberta dentro de muitas histórias aparentemente convencionais e coerentes. Talvez a outra coisa interessante sobre o que Cowen chama de sua suspeita da narrativa é que se trata de uma suspeita de prazer, superfícies, trivialidade, detalhes "sem sentido", talvez da própria feminilidade.

Quero abordar agora a excepcionalidade em algumas histórias de minha mais recente pesquisa sobre o HIV. É claro que a excepcionalidade no caso do HIV se aplica a fenômenos vividos e não somente a histórias. Mas existe uma persistente discussão no ramo do HIV sobre o grau de excepcionalidade do HIV - trata-se simplesmente de outra situação de baixos recursos de saúde, iniquidade de gênero, subdesenvolvimento e pós-colonialismo? Existe algo excepcional em relação à sua escala, sua estigmatização e seus efeitos? Ou esta pretensão "excepcionalista" simplesmente é levantada para extorquir dinheiro de governos do Norte e de ONGs internacionais enquanto a epidemia se atenua e se transforma em mais um problema de saúde persistente? O HIV é agora apenas diferencialmente tratável de acordo com os recursos, à semelhança de muitos outros problemas de saúde, com implicações fortes mas não singulares 
em termos de recursos e sem um provável novo interesse teórico para os pesquisadores sociais? (De Waal, 2006).

Em minha mais recente rodada de entrevistas na investigação do apoio em casos do HIV no Reino Unido, entrevistei 46 pessoas que vivem com o HIV -5 das quais entrevistei antes- e encontrei uma forte tensão entre a naturalização narrativa do HIV -sua gestão mediante a medicalização, normalização e mercantilização- e a ruptura narrativa desses processos por histórias que falam de ser preterido por tratamento, serviços sociais, representações públicas da epidemia, por histórias que falam de vidas cotidianas vividas na exclusão de ou às margens de famílias, trabalho, relacionamentos, cidadania, e por histórias que falam de resistência à medicalização, de recusa a ser normal, de rejeição de mercados ou do estabelecimento de seu próprio (Squire, 2010). Essas rupturas efetivamente demonstram o excepcionalismo do HIV, embora eu creia que haja formas melhores de descrevê-lo. Pois realmente não se trata de um excepcionalismo geral do HIV do tipo que se costumava advogar, mas, antes, de características muito específicas: a história particular da doença e das mortes em torno deste problema de saúde; sua particular imprevisibilidade médica e dificuldade de tratamento; sua estigmatização particular e contínua, sexualizada, baseada em gênero, homofóbica em muitos contextos; e os novos fenômenos fisiológicos e psicossociais particulares em torno deste problema de saúde relativamente jovem que sempre vêm surgindo e a específica abdicação não expressa do tratamento do HIV em países de baixa renda (Nguyen, 2010) e suas limitações em muitos outros contextos. Embora se possam ver esses padrões narrativos em diferentes contextos da epidemia, que se desenvolveram ao longo da última década e meia de acesso ao tratamento no Ocidente, a tensão narrativa, creio eu, aumentou no contexto contemporâneo de austeridade, de modo que muitas das histórias nas entrevistas pareciam ser histórias que falam de viver em uma recessão e não de viver com o HIV, acompanhadas de momentos concomitantes de alternativas narrativas em que as pessoas entrevistadas encontraram maneiras de estruturar diferentemente suas vidas neoliberais.

Quero apresentar algumas histórias cuja excepcionalidade narrativa também é uma maneira de transmitir estas particularidades da epidemia do HIV. Primeiramente, esta é uma história que Robert (todos os nomes são pseudônimos) contou -não pela primeira vez-sobre como se encontrou com seu namorado.

Robert - Sim, quero dizer que é bastante engraçado, porque ele é alguém que eu tinha visto por ai durante anos, alguém pelo qual me sentia atraído, e então entramos em contato online e então, há um 
aplicativo no iPhone, chamado Grindr, e lhe mandei uma mensagem no Grindr, e estávamos conversando ali e então pensei, "bem, eu vou abrir o jogo", e, assim, revelei que eu era positivo, e ele disse, "oh, eu também sou", e continuei, "oh legal", e ele disse "essas não são as palavras que eu usaria, mas sei o que você quer dizer".

Esta é uma história, que o próprio Robert conta como atípica, de romance e revelação através do envio de mensagens -Robert diz, mais tarde, que acha que esse meio dá às pessoas um espaço para responder que a revelação face a face não oferece-, e de uma valoração transgressiva do HIV como "legal". $\mathrm{O}$ agora namorado de Robert considerou a última mensagem um pouco politicamente incorreta; Robert, como uma série de outros entrevistados, falou algumas vezes sobre sua maneira leviana e "negramente" humorística de falar do HIV, algo que nem todas as pessoas soropositivas, muito menos todas as pessoas, compartilham. Muitos ouvintes, de todos os status positivos de HIV, conseguem compreender uma história que termina com o alívio de duas pessoas não terem de lidar com a sorodiscordância em seu relacionamento chamar isso de "legal", para muitos, contradiz uma seriedade apropriada. No entanto, essa história de "legal" funciona para exemplificar algo realmente específico sobre a epidemia nesta época, nessas circunstâncias: que pessoas soropositivas que estão sendo tratadas podem considerar e irão considerar e às vezes fazem sexo desprotegido um com o outro, como Robert descreve mais tarde -e talvez com pessoas que são soronegativas- porque suas cargas virais baixas tornam os riscos de infecção muito pequenos. Isso, em um contexto contínuo de acusar as pessoas soropositivas por seu estado de saúde e de discriminá-las, pode constituir um pensamento perturbador - as pessoas que vivem com o HIV deveriam ter os mesmos prazeres que qualquer outra pessoa? E se as pessoas que vivem com o HIV podem ser tão saudáveis que o sexo desprotegido não é arriscado, como podem ser entendidas como reconfortantemente, punitivamente diferentes de outras pessoas?

$\mathrm{O}$ "caráter legal" que Robert menciona também é relacionado por ele mais tarde à sua capacidade e à de seu namorado de cuidarem um do outro, e aqui novamente a excepcionalidade desta história aponta para algo bastante particular em relação à epidemia contemporânea no Reino Unido: que ela é invisibilizada, medicalizada e estigmatizada a tal ponto que muito cuidado não médico é efetivamente oferecido por pessoas soropositivas a outras pessoas soropositivas. Talvez outra coisa que seja transgressiva em relação a esta história é que os leitores vislumbram nela algo das relações sociais seriamente não "legais" que pessoas soropositivas muitas vezes têm com aquelas de outros status, o preço pessoal cobrado pela exclusão e discriminação. 
Quero lhes apresentar agora uma história realmente diferente, de novo altamente específica e que, desta maneira, revela os contextos contemporâneos da epidemia bem como escapa deles em sua idiossincrasia - porém que funciona mais como exceção radical e menos como exemplificação. Aqui está Dorothy, uma mulher soropositiva, em seus 40, originária do sul da África; ela vive no Reino Unido e nos conta de suas dificuldades com a filha e de como morreu o filho:

Dorothy - Ela (a filha), ainda está [no país], sim. Tentei trazê-la, mas não deu certo e então pensei, pensei que ela estava na escola primária lá, indo para a escola secundária, de maneira que eu não tinha procurado um lugar para ela, porque achei que seria possivel, mas não foi, eu tive de voltar de novo para minha irmã e pedir-lhe para ficar com a menina, de forma que ela a recebeu, e então, certa vez, ela a surrou, sabe, com um couro cru, sabe, eles colocam um pedaço de pau na ponta, ela a surrou, minha filha nunca me contou, ela a surrou e colocou sal e colocou pimenta, minha filha nunca me contou, eu só fiquei sabendo disso quando ela foi visitar a irmã do pai dela, foi então que viram as cicatrizes e lhe perguntaram e então ela lhes contou que minha irmã a tinha surrado e que ela tinha roubado um dinheiro dela, ela não queria que eu lhe mandasse dinheiro, mas eu disse que quando eu estava indo para a escola meus pais costumavam me dar 50 centavos pelo menos, sabe... Acho que não fui uma mãe presente para meus filhos, sabe, e meu filho morreu enquanto dormia e acho que ele estava jejuando. Não sei por que, eu sei que me contaram que, uma vez, ele queria cometer suicidio, e eu me arrependo de lhe ter dito para cuidar de sua irmã, sabe, e me arrependo de ter dito isso a ele, porque não sei por que ele quis cometer suicídio, sabe, vendo as pessoas na África que são soropositivas.

Esta é uma sequência narrativa em uma complexa história contada em uma entrevista que soma dificuldade à perda, à culpa, à luta. Ela não é mais difícil em conteúdo do que outras histórias na entrevista. No entanto, ela é mais problemática para entender.

Há grupos de histórias que falam de migração, detenção, abandono de filhos, de viver à base de tickets e ser diagnosticado com atraso, e a entrevista de Dorothy contribui para todas elas. Estas histórias dela funcionam como uma espécie de janela sobre a gama de problemas que migrantes soropositivos enfrentam, problemas tão amplos e intensos que o próprio HIV, muitas vezes, desaparece do quadro. Essas particularidades nos contam que o HIV, frequentemente, não está no centro das histórias das pessoas; elas expõem a complexidade corrente desses outros fatores bem como do próprio HIV. 
Além disso, muitas destas histórias representam uma depressão que não pode ser generalizada ou suprimida pela narrativa, que simplesmente é repetida de maneira constante, que é inevitavelmente muito perturbadora de se ouvir e muito mais de se contar - mas que é altamente compreensível. Entretanto, algumas das histórias de Dorothy - como essas acima - também são excepcionais de formas que não transmitem compreensão. Essas histórias de sua irmã e seus filhos contêm muitos elementos que são inteiramente idiossincráticos. Ela tem uma relação ambivalente e muito específica com sua irmã, particularmente mas não só em torno do HIV; tem uma filha que tentou protegê-la de enviar dinheiro ao roubar dinheiro; o filho dela, que tinha uma doença grave não relacionada com o HIV, pensou em suicídio porque, teme ela, sua ordem de que ele cuidasse de sua irmã o levou a saber que a mãe tinha HIV, e a temer que - como outras pessoas soropositivas que ele tinha conhecido - ela morresse; talvez seu jejum tenha sido expiatório.

Essas histórias excepcionais não são ilustrativas. Elas revelam aspectos da epidemia como relacionamentos em famílias afetadas pelo HIV, e através de gerações, que exigem explicação, sem que nos contem muito sobre eles. No entanto, é importante saber dessa variabilidade, mesmo que, no presente, reconhecê-la é tudo que podemos fazer; de outra maneira, nós nos satisfaríamos com as histórias que conhecemos, as familiares, as confortáveis que não se coadunam com a confusão da vida.

É neste ponto de radical excepcionalidade que a pergunta do que é a narrativa se aproxima de outra pergunta: para que serve a narrativa? Como sugere Butler (2006), isto é, no caso de narrativas pessoais, fundamentalmente uma questão moral. As autonarrativas nos colocam eticamente em resposta ao chamado social de sermos sujeitos morais. Mas a ordem narrativa moral é um terreno contestado e, às vezes, incompreensível. As exceções radicais da narrativa nos levam a pensar sobre a particularidade de histórias como características éticas, e não só representacionais.

\section{Referências}

BARTHES, R. Camera lucida. New York: Vintage Classics, 2009.

BRUNER, J. Culture and human development: a new look. Human Development, v. 33, p. 344-355, 1990.

BUTLER, J. Giving an account of oneself. New York: Fordham University Press, 2005.

CORNELL, D. Derrida: the gift of the future. Differences, v. 16, n. 3, p. 68-75, 2005.

COWEN, T. Be suspicious of stories. 2009. <http://www.ted.com/talks/tyler_cowen_ be_suspiciuos_of_stories.html $>$ (8 mar. 2012). 
CRAIB, I. Narratives as bad faith. In: M. Andrews; S. Sclater; C. Squire; A. Treacher (Orgs.). Uses of narrative. New Brunswick: Transaction, 2004.

DE WAAL, A. Aids and power. London: Zed Books, 2006.

DERRIDA, J. Truth in painting. Chicago: Chicago University Press, 1987.

FRIED, M. Forward. In: D. Lessing. Laocoan. Baltimore: Johns Hopkins University Press, 2012.

FROSH, S. After words. London: Palgrave, 2002.

HYVÄRINEN, M.; HYDÉN, L. C.; SAARENHEIMO, M.; TAMBOUKOU, M. (Orgs.). Beyond narrative coherence. Amsterdam: John Benjamins Publishing, 2010.

KRAUSS, R. Cindy Sherman's gravity: a critical fable. Artforum International, v. 32, n. 1, p. 163-166, 1993.

KRISTEVA, J. Powers of horror. New York: Columbia University Press, 1984.

LINCOLN, A.; GUBA, E. Naturalistic inquiry. Newbury Park: Sage Publications, 1985.

MACGREGOR, N. A history of the world in 100 objects. London: Allen Lane, 2011.

MCADAMS, D. The redemptive self. New York: OUP USA, 2006.

MISHLER, E. Craftartists. Cambridge: Harvard University Press, 1999.

MITCHELL, W. Iconology. Chicago: Chicago University Press, 1987.

MULVEY, L. Death 24 X a second. London: Reaktion Books, 2006.

NGUYEN, V.-K. The republic of therapy. Chapel Hill: Duke University Press, 2010.

NUSSBAUM, M. Victims and agents: what Greek tragedy can teach us about sympathy and responsibility. Boston Review, 20 dez. 1998.

SCHOR, N. Reading in detail. New York: Routledge, 2006.

SPENCE, J. Cultural sniping. London: Routledge, 1995.

SQUIRE, C. Being naturalized, being left behind: the HIV citizen in the era of treatment possibility. Critical Public Health, v. 10, n. 4, p. 401-427, 2010.

Recebido em: 26 ago. 2013

Aprovado em: 14 abr. 2014

Autora correspondente:

Corinne Squire

School of Law and Social Sciences

University of East London

4-6 University Way

London E16 2RD. 